\title{
The Game Relationship Between Government and Individual in China Rural Endowment Insurance
}

\author{
Wang Ping, Wang Jing* \\ School of Management, Xi'an University of Science and Technology, Xi'an, China \\ Email address: \\ 1728952415@qq.com (Wang Jing) \\ ${ }^{*}$ Corresponding author \\ To cite this article: \\ Wang Ping, Wang Jing. The Game Relationship Between Government and Individual in China Rural Endowment Insurance. International \\ Journal of Management and Fuzzy Systems. Vol. 4, No. 1, 2018, pp. 1-6. doi: 10.11648/j.ijmfs.20180401.11
}

Received: December 26, 2017; Accepted: January 23, 2018; Published: February 11, 2018

\begin{abstract}
With the aging problem aggravated gradually, the pension problem has aroused the concern of many scholars and it become a very unique social problem in china. In the future development, the way to solve the aging problem will be largely through the way of pension insurance. Based on the large difference in China region, this paper chooses the rural areas with more serious aging problems, and uses the game theory to establish the complete information static game to discuss the game relationship between the government and the individual in the rural endowment insurance. Finally, on the basis of certain assumptions, a complete information static game model of government and individual in rural endowment insurance is established, and this paper solve the Nash equilibrium (solution) and utility of the game model in the range of ZZ (the government's profit value when the government chooses to provide the strategy) and the GG (personal benefit value of the individual's choice of payment strategy). Finally, this paper discusses the assumptions and gives the prospect to the further development of the model.
\end{abstract}

Keywords: Pension Problem, Rural Endowment Insurance, Complete Information Static Game, Nash Equilibrium

\section{Introduction}

According to the Ministry of Human Resources and Social Security statistics, the number of elderly people aged 60 years old and older has reached 222 million in 2015, accounting for $16.1 \%$ of the total population. [1-3] Optimistically speaking, the proportion of rural people aged 60 years old and older in China's rural and urban areas is $15.6 \%$ and $9.0 \%$ respectively, and 2050 will be $32.7 \%$ and 21.2\%. [1-3] China's population aging into the accelerated development stage, pension has become a general need to maintain the life quality of the elderly and to relieve the care pressure of the elderly family members. [4] Therefore, optimizing the establishment of our country's pension system has become one of the most important issues currently, and the pension will largely become a breakthrough in the issue. [5] In China, with the acceleration of urbanization, the outflow of rural labor force has become more and more serious, so the rural pension problem has become the most important cause of pension.
[6]

The development of many developed countries in the world are also faced with the problem of population aging, countries according to national conditions to take a different approach to deal with the problem respectively, and established the old-age insurance system is widely used. For example, the establishment of three levels of insurance model in Switzerland, to take tax-free measures to encourage personal savings pension in Canada, the establishment of the central provident fund system to solve the pension problem in Singapore, these countries in the pension problem has achieved good results. [5] In contrast, China's current pension problems faced is more complex and grim than any other countries, so our country not only should learn from other countries' successful experience, but also need explore a set of scientific pension system and establish a viable pension insurance system with China's national conditions. [6]

China's rural old-age insurance is also a lot of contradictions, and these problems only rely on the government is very difficult to solve. [7] On the one hand, 
everyone is a participant in the social and economic development, is the main responsibility of the community, the development of individuals need a good social environment and economic environment, social pension problem's highlights will produce big influence for everyone undoubtedly. [8] On the other hand, the individual should have a sense of responsibility for the social existence problems. So each of us should actively participate in the construction of old-age insurance, and establish a positive cooperation relationship with Government to promote the development of pension. [9] In reality, there is a clear game relationship between individuals and governments in participating in pension insurance activities.

The collection of old-age insurance have a certain difference between the urban and rural areas, the pension insurance generally in accordance with the principle: "personal payment - based, government subsidies supplemented", but in practice the individual's enthusiasm is not high, then the government does not support in turn, and it also will affect the enthusiasm of the farmers in turn, so the successful establishment of the endowment insurance system in the rural areas may still have a long way to go. [10-11] Based on the importance of the establishment of the old-age insurance system, coupled with the rural areas' backward, the old people's care is difficult to do more. To make a valuable leap in the old people's care, we should only catch the pension which is an important breakthrough. [12] This paper will use the knowledge and method of game theory to construct a complete information static game model of government and individual in rural endowment insurance, and analyze the game problem of rural old-age insurance.

\section{Method Introduction}

There are two steps when use the game theory to analyze this problem. Firstly, establish the game model, that is defines of the game participants, the game rules, the ending and the utility. Then, the Nash equilibrium of the model is found as the prediction of the player's behavior. [13-16] This paper will build a complete information static game model of government and individual in rural endowment insurance. This chapter introduces this method.

\subsection{The Concept of Complete Information Static Game}

Complete information static game refers to the information for the two sides of the game is completely open to the case, and the two sides in the game decision is the same time or not at the same time but before the other party to do the decision the side is unknown, such a game is the complete information static game. [16]

In game theory, the game is divided into four categories according to whether the game is static or dynamic and whether it is complete or incomplete. The game is divided into four categories: complete information static game, complete information dynamic game, incomplete information static game, incomplete Information dynamic game. [16] And each type of game corresponds to a different solution, where the complete information static game corresponds to the Nash equilibrium. [16] The solution of game is the game theory to predict the behavior of the game participants under given game scenario, so solving game is the core of game theory. It is precisely because of this, in dealing with practical problems, the problem will generally be simplified into a complete information static game, in order to get Nash equilibrium.

\subsection{Necessary Equilibrium of Completely Information Static Game (Solution)}

The equilibrium based on the two basic assumptions of reason and common understanding depicts the steady state of the game, the equilibrium is the solution of the game and the prediction of the game participants. Nash equilibrium is a prediction of the game participants in completely information static game. It is called equilibrium because it is stable. Under the equilibrium, no player will unilaterally deviate, because the deviation will not improve the utility of any player. [16] Nash equilibrium has been able to be widely used, an important reason is that it exists in a large number of game models.

General solution Nash equilibrium has the following methods: enumeration method, strategy equivalent method (crossed method), simultaneous equation method and trial-error induction method. [16] Among them, the enumeration method is suitable for simple and limited number of strategies, it is a simple and mechanical method to find Nash equilibrium; the strategy equivalence method is a simple method to balance the mixed strategy in the game with limited number of strategies; and the simultaneous equation method means that when the utility function of the player is continuous for the strategy, we can generally solve the method of solving the simultaneous equations based on the optimal first-order condition. [16]

\section{Model Establishment}

A game consists of four basic elements: game participants, game rules, game utility and game outcome. [13-16] This chapter will start from the model hypothesis, step by step analysis of the establishment of the practical problem of the game model.

\subsection{Model Hypothesis}

Completely information static game in game theory needs to meet rational and common cognition two prerequisites. In this practical question, we make the following assumptions:

Hypothesis 1: The government and the individual are rational, all with the principle of their own interests maximize during the participation in the game;

Hypothesis 2: The decision made by the government and the individual is at the same time, or not at the same time but not known to the other side before making a decision;

Hypothesis 3: Neither the government nor the individual has invested in the pension system, the two sides do not 
produce any effect.

Under these three assumptions, this practical problem can be dealt with as a game problem that meets the premise of complete information static game.

\subsection{Game Participants}

\section{(1) Participant 1: Government}

In the economics, "the government is not an abstract concept, it is a specific behavioral institutions, the government through the provision of adequate and necessary public goods to maintain the coordinated functioning of social life. High-quality government administration needs a better public policy and higher productivity." In many aspects of the pension business, the government has played a leading role in management. [17] Taking the payment and management of the old-age insurance premium as an example: the pension payment formed by the individual payment is managed by the state to establish a personal account; when the elderly reaches the age of 65 , they are designated by the state or issued by themselves to ensure that the pension is paid to the elderly hands and to meet the needs of the elderly life. So the government plays the role of the leader and managers in the pension system and the government's pension behavior is the key to the operation of the pension system. Therefore, the government in the implementation of the pension policy and other management functions which related to the pension, its behavior directly determines whether the pension policy can be effectively implemented and implemented. So in the pension insurance game model, the government is a very important participant.

\section{(2) Participant 2: Individual}

Individuals also play an important role in our pension system. First, the government's policy requires a personal response, the public participation in the policy can only play its real role; Second, everyone need to consider their own personal endowment within a reasonable acceptable range, this is very necessary. In the process of running the pension system, individuals pay pensions and make recommendations to promote the pension system. Individuals can pursuit their own economic interests, at the same time, it increased the personal old age income and benefits. Therefore, the individual is also an important participant in the pension system.

\subsection{Game Rules}

For the pension system, it is generally supported by government contributions and the other part is paid by the individual. Therefore, in this game, for the game participants government, the government has to provide money and do not provide money two strategies; corresponding to the game participants individual, the individual has the payment and not pay two strategies.

\subsection{The Utility of the Game}

Because there is no actual data, we make the following assumptions about the utility values that may appear in the model. On the basis of 3.1 Hypothesis 3(Neither the government nor the individual has invested in the pension system, the two sides do not produce any effect.), we analyze other possible scenarios.

If the individual not pay the pension, and the government provide the pension. In this case, the government provides a pension and get a certain benefit, recorded as GG (government $\mathrm{G}$ to provide money, the government $\mathrm{G}$ obtained utility value recorded as GG); individuals through government funding to ease the pressure, the benefits Recorded as GI (government G to provide money, individual obtained by the utility value recorded as GI).

If the government does not provide the pension, the individual pay the pension. In this case, the individual to pay pension, and obtain premiums and benefits during their old age, recorded as II (individual I to pay insurance premiums, individual I obtained by the utility value as II); government because of personal to pay the premium and ease a certain pressure to get the benefits, recorded as IG (individual I to pay insurance premiums, government $\mathrm{G}$ obtained by the utility value as IG).

In short, we use the initials of both sides of the game to briefly represent the utility of both sides in the game. Where the government chooses to provide the pension and the government gains the value is GG; the government chooses to provide the pension and the individual benefit value is GI; the individual chooses to pay the pension and the government gains the value is IG; the individual chooses to pay the pension and the individual gains the value is II.

Here, we need to explain in particular that GG (the government chooses to provide the pension and the government gains the value) and II (the individual chooses to pay the pension and the individual gains the value) are affected by the cost-benefit structure, they can be positive or negative. However, to the GI (the government chooses to provide the pension and the individual benefit value) and IG (the individual chooses to pay the pension and the government gains the value), because there is no cost value only income value, so GI and IG are positive. [18] That is, GG and II can be positive or negative; GI and IG can only be positive.

\subsection{Game Outcomes}

After analyzing the rules and the utility of the game, we can get the following four kinds of game outcomes on the basis of the government's provide or not-provide the pension and individual's pay and not-pay:(A) individual-pay, government-provide money, this time the individual's utility is II+GI, the government's utility is GG+IG;(B) individual-pay, government-not-provide money, this time the individual's utility is II, the government's utility is IG;(C) individual-not-pay, government-provide money, this time the individual's utility is GI, the government's utility is GG;(D) individual-not-pay, government-not-provide money, this time the individual's utilityis0, the government's utility is 0 .

We make the game outcomes and it's utility as follows, that is the game model of government and individual in the 
rural endowment insurance.

Table 1. The Utility Matrix of Government and Individual Game Models in Rural Endowment Insurance.

\begin{tabular}{llll}
\hline \multirow{2}{*}{ Utility matrix table } & \multicolumn{2}{l}{ Government (G) } \\
\cline { 3 - 4 } & (1) Provide & (2) Not-Provide \\
\hline \multirow{2}{*}{ Individual (I) } & (1) Pay & II+GI; GG+IG & II; IG \\
& (2) Not-Pay & GI; GG & $0 ; 0$ \\
\hline
\end{tabular}

\section{Model Solving}

From table 1, if we want to solve the game model of the government and the individual in the rural endowment insurance, we must discuss the size of each utility value. Although the aging to the government is a test of the ruling, but the pension is the inevitable problem of each person's own. [19] Therefore, this article make the individual as the starting point, three situation to solve the government and individual in the rural endowment insurance in the game model, and solve its Nash equilibrium. The following three cases are analyzed in depth: II $>0$; II $<0$; II $=0$.

\subsection{When the Individual Chooses to Pay the Pension, he Gains the Value II $>0$}

When $\mathrm{II}>0, \mathrm{II}+\mathrm{GI}>\mathrm{GI}$, indicating that individuals in the payment decisions to obtain a positive effect, income is greater than the cost, so at this time individuals choose the pay strategy is the best choice. When the individual choose the pay strategy, under this premise, we have to analyze the government's choice, because GI $>0$ and this time II $>0$, so II + GI $>$ II. Therefore, the government's choice is provide or not-provide will depend on the positive or negative of GG. The following we are divided into three cases to discuss.

(A) When $G G>0$

When $\mathrm{GG}>0, \mathrm{GG}+\mathrm{IG}>\mathrm{IG}$, indicating that the government in the provide decisions to obtain a positive effect, income is greater than the cost, so at this time government choose the provide strategy is the best choice, this time the game to achieve Pareto optimal Nash equilibrium (Pay, Provide), the utility is (II+GI, GG+IG). At this point, the individual's utility II+GI and the government's utility ZZ+GZ are the two sides can get the maximum utility.

(B) When $G G<0$

When $\mathrm{GG}<0, \mathrm{GG}+\mathrm{IG}<\mathrm{IG}$, indicating that the government in the provide decisions to obtain a negative effect, income is less than the cost, so at this time government choose the not-provide strategy is the best choice, this time the game to achieve Nash equilibrium (Pay, Not-Provide), the utility is (II, $\mathrm{IG)}$.

\section{(C) When $G G=0$}

When $\mathrm{GG}=0, \mathrm{GG}+\mathrm{IG}=\mathrm{IG}$, indicating that the government in the provide decisions did not get any effect, only the cost and no income, so at this time government choose the not-provide strategy is the best choice, this time the game to achieve Nash equilibrium (Pay, Not-Provide), the utility is (II,
IG).

\subsection{When the Individual Chooses to Pay the Pension, he Gains the Value II $<0$}

When $\mathrm{II}<0$, II $+\mathrm{GI}<\mathrm{GI}$, indicating that individuals in the payment decisions to obtain a negative effect, income is less than the cost, so at this time individuals choose the not-pay strategy is the best choice. When the individual choose the not-pay strategy, under this premise, we have to analyze the government's choice, because GI $>0$, therefore, the government's choice is provide or not-provide will depend on the positive or negative of GG. The following we are divided into three cases to discuss.

(A) When $G G>0$

When $\mathrm{GG}>0$, indicating that the government in the provide decisions to obtain a positive effect, income is greater than the cost, so at this time government choose the provide strategy is the best choice, this time the game to achieve Nash equilibrium (Not-Pay, Provide), the utility is (GI, GG).

(B) When $G G<0$

When $\mathrm{GG}<0$, indicating that the government in the provide decisions to obtain a negative effect, income is less than the cost, so at this time government choose the not-provide strategy is the best choice, this time the game to achieve Nash equilibrium (Not-Pay, Not-Provide), the utility is $(0,0)$.

(C) When $G G=0$

When $\mathrm{GG}=0$, indicating that the government in the provide decisions did not get any effect, only the cost and no income, so at this time government choose the not-provide strategy is the best choice, this time the game to achieve Nash equilibrium (Not-Pay, Not-Provide), the utility is $(0,0)$.

\subsection{When the Individual Chooses to Pay the Pension, he Gains the Value $I I=0$}

When $\mathrm{II}=0, \mathrm{II}+\mathrm{GI}=\mathrm{GI}$, indicating that individuals in the payment decisions did not get any effect, only the cost and no income, so at this time individuals choose the not-pay strategy is the best choice. When the individual choose the not-pay strategy, under this premise, we have to analyze the government's choice, because GI $>0$, therefore, the government's choice is provide or not-provide will depend on the positive or negative of GG. The following we are divided into three cases to discuss.

\section{(A) When $G G>0$}

When $\mathrm{GG}>0$, indicating that the government in the provide decisions to obtain a positive effect, income is greater than the cost, so at this time government choose the provide strategy is the best choice, this time the game to achieve Nash equilibrium (Not-Pay, Provide), the utility is (GI, GG).

(B) When $G G<0$

When $\mathrm{GG}<0$, indicating that the government in the provide decisions to obtain a negative effect, income is less than the cost, so at this time government choose the not-provide strategy is the best choice, this time the game to achieve 
Nash equilibrium (Not-Pay, Not-Provide), the utility is $(0,0)$.

(C) When $G G=0$

When $\mathrm{GG}=0$, indicating that the government in the provide decisions did not get any effect, only the cost and no income, so at this time government choose the not-provide strategy is the best choice, this time the game to achieve Nash equilibrium (Not-Pay, Not-Provide), the utility is $(0,0)$.

\subsection{Summary}

Through solving the game model of the government and individuals in rural endowment insurance in this chapter, we get the Nash equilibrium of the game model under each value range of the utility value, which is summarized as follows:

Table 2. Summary of the Results of the Game Model of Government and Individuals in Rural Pension Insurance.

\begin{tabular}{llll}
\hline Summary of Results & Equilibrium Solution & The Final Utility Value \\
\hline \multirow{3}{*}{$\mathrm{II}>0$} & $\mathrm{GG}>0$ & (Pay, Provide) & (II+GI, GG+IG) \\
& $\mathrm{GG}<0$ & (Pay, Not-Provide) & (II, IG) \\
& $\mathrm{GG}=0$ & (Pay, Not-Provide) & $(\mathrm{GI})$ \\
& $\mathrm{GG}>0$ & (Not-pay, Provide) & $(0,0)$ \\
$\mathrm{II}<0$ & $\mathrm{GG}<0$ & (Not-pay, Not-Provide) & $(0,0)$ \\
& $\mathrm{GG}=0$ & (Not-pay, Not-Provide) & $(\mathrm{GI}, \mathrm{GG})$ \\
& $\mathrm{GG}>0$ & (Not-pay, Provide) & $(0,0)$ \\
$\mathrm{II}=0$ & $\mathrm{GG}<0$ & (Not-pay, Not-Provide) & $(0,0)$ \\
& $\mathrm{GG}=0$ & (Not-pay, Not-Provide) & \\
\hline
\end{tabular}

Notes: The government chooses to provide the pension and the government gains value is GG; the government chooses to provide the pension and the individual gains value is GI; the individual chooses to pay the pension and the government gains value is IG; the individual chooses to pay the pension and the individual gains value is II.

\section{Results-Discussion}

We know that the complete information static game in the game theory needs to satisfy two preconditions of rationality and common understanding. This paper makes two assumptions: both the government and the individual are rational, both of them are based on the principle of maximizing their own interests in the game(Hypothesis 1). The decisions made by the government and the individual are simultaneous or not at the same time but not known to the other side before making a decision(Hypothesis 2). The following are two assumptions as a starting point for the results to be discussed.

(A) Hypothesis 1: The government and the individual are rational.

First, it is not possible for a country's leading government to make decisions based solely on whether they are benefiting or not, but on the careful consideration of many influential factors. That is, whether the government meets the principle of rationality needs to be studied carefully.

Second, everyone who is a member of the general public can vary widely. Some can be rational enough, but farmers in rural areas may have a limited share of cognitive capacity. Therefore, as another individual participant in the game, it is not always possible to foresee and believe the so-called benefits. It is yet to be discussed whether or not individuals actually satisfy the principle of reason.

(B) Hypothesis 2: Government and individuals make decisions is at the same time

We assume that the decisions made by the government and the individual are simultaneous or not at the same time but not known to the other side before making a decision In fact, the government and individuals that are both players do not make decisions at the same time. As a policy maker, the government will certainly inform the public before people make decisions, and then the public make decisions. Therefore, the hypothesis of simultaneity is too idealistic.

Therefore, in order to better fit the actual processing problems, we can consider the use of complete information dynamic game to continue to deal with the game relationship, this article will not go into details [20].

All in all, the game relationship between government and individuals in rural pension insurance does exist. This paper analyzes the Nash equilibrium of the game model under the assumption that the game model satisfies the complete information static game, and draws the conclusion. Hopefully, in a serious regional difference of China, the government will grasp the characteristics of various regions and establish an endowment insurance system so as to reduce the pressure from aging and achieve better economic development.

\section{Conclusion}

In this paper, we establish and solve the game model between the government and individuals in rural old-age insurance, the corresponding Nash equilibrium and utility value reached by the government and individuals at various utility values are obtained in table 2 . From the results, it is easy to know that, under normal circumstances, the government and individual's strategies are depend on whether the respective input costs can be increased or preserved. Therefore, in view of the imbalance of economic development in our country, rural endowment insurance can adopt different ways according to different situations.

\section{Fund Project}

National Social Science Fund Project "A Study on the Dynamic Evolution of Family Structure and Intergenerational Support for Rural Elderly People"(17BRK020); National Social Science Fund Project "Follow-up Study on the Intergenerational Relationship between the Elderly and 
Children, Grandsons in Rural China"(14CRK003); National Natural Science Foundation of China "A Study on the Dynamic Evolution of Livelihoods and Welfare of Rural Elderly and Family Support Policies"(71573207).

\section{References}

[1] Wu Yushao, Dang Junwu. China's Aging Industry Development Report (2014) [J], Beijing: Social Science Document Publishing House. 2014.

[2] Ministry of Civil Affairs. Statistical Communique on Social Service Development 2014 [EB / OL], 2015: 6-10.

[3] Yang Yansui. China's Aging Society and Pension Development Report (2013) [M], Beijing: Tsinghua University Press. 2013: 98-100.

[4] Jiang Dan. To Deal with the Aging Population "Six Policy" [J], Learning TimesPress. 2015 (3).

[5] Zheng Gongcheng. China's Social Security Reform and Development Strategy [M], Beijing: People's Publishing House. 2011: 64-67.

[6] Tang Jun. The Status Quo, Problems and Prospects of China's Elderly Services [J], Journal of the National Administration. 2015 (3).

[7] M. Martinboyer. Centralizing Insurance Fraud Investigation [J], The Geneva Papers on Risk and Insurance Theory. 2000 (25): 159-178.

[8] Song Wang, Zhengzheng Sheng. China's Pension Insurance in the Game between Government and Enterprises [J], Fujian Administration Institute of Fujian Institute of Economic Leaders. 2004 (2): 45.

[9] Cheng Gongcheng. Social Security [M], Beijing: China Labor and Social Security Publishing House. 2005.
[10] Lu Jing. Study on the Relationship between the Game of Local Governments in Our Country and the Basic Old-age Insurance [J], Science and Technology. 2008 (10): 118.

[11] Weirich P. Equilibrium and Rationality: A Game Theory Modified by Decision Rules [M], Beijing: Economic Science Press. 2000: 12.

[12] Amitai Etzioni. The Fightagainst Fraud and Abuse: Analyzing Constituent Support [J], Journal of Policy Analysis and Management. 1982 (Autumn): 26-38.

[13] Xie Zhiyu. Economic Game Theory [M], Shanghai: Fudan University Press. 2006.

[14] Zhang Weiying. Game Theory and Information Economics [M], Shanghai: Shanghai People's Publishing House. 1996.

[15] Shi Xiquan. Game Theory [M], Shanghai: Shanghai University of Finance and Economics Press. 2002.

[16] Tu Zhiyong. Game Theory [M], Beijing: Peking University Press. 2009.

[17] Zheng Gongcheng. Social Security [M], Beijing: Commercial Press. 2000.

[18] Camerer C. F. (He Jingtong, Na Yi, Ji Jiapeng et al.) Behavioral Gaming: An Experimental Study of Strategic Interactions [M], Beijing: Renmin University Press. 2006.

[19] Wu Fan. Analysis on the Supply and Demand of the Aged Resources in China and the Intervention Model of Social Work [J], Journal of Population Sciences. 2007 (3): 47-51.

[20] Li Min, Zeng Yongquan. Government and Enterprises in the Social Pension Insurance in the Game[J], Journal of Huazhong University of Science and Technology (Social Science Edition) 2007. 